\title{
Preface and Acknowledgment to First German Edition
}

Our current world would be inconceivable without explosives. In munitions, propellants, and pyrotechnics they serve the protection and defense. However, in wrong possession ammunition and explosives can cause chaos and annihilation.

Less controversial is the use of explosives in the development of our human habitats. Roads, tunnels, and basically any construction operation on rocky ground are unimaginable without the use of explosives as are demolition or mining operations above, underground, and offshore. Explosives help to easily forge metal stock and weld-complicated metal combinations that would otherwise not join. Almost forgotten is the massive use of explosive rivets in the manufacture of aircrafts in the mid-twentieth century. Gas generators in nearly each automobile today protect passengers and have saved countless lives and have prevented severe injuries. Flares and smoke serve as distress signals. Fireworks crest festive and holidays. Without the plentiful energetic materials in chemical propulsion, actuators, separating bolts, and cutting cords the exploration of space would be impossible. Finally, the use of explosives facilitates the production of new materials (SHS, detonation synthesis) that are inaccessible by other means.

A German encyclopedia for high explosives, propellants, and pyrotechnics, offering direct access to the primary literature was missing so far and is presented in this book. On 460 pages, there are 590 entries with 133 tables, 82 figures and more than 200 structural formulas, and nearly 900 references.

The selection of entries naturally is subjective and is based on my current and previous field of work.

A book claiming to be an encyclopedia can and must not be the work of a single individual. It is hence that I am thankful to many current and former colleagues for hints, information, and comments.

Representative for many, I would like to thank physicist Mr. Roland Wild, retired deputy director of the Heimerzheim branch of the Wehrwissenschaftliches Institut für Werk- Explosiv- und Betriebstoffe, for reviewing the manuscript, for his many valuable comments, and for his efforts to write a foreword for this book.

I now wish you happy reads and lookups and would be very glad to receive your comments on errors and necessary amendments for future editions.

Kaiserslautern, November 2017

Ernst-Christian Koch 
